03. FELIPE POHL SOUZA

Defesa de Tese: 02/02/97

\section{TÍTULO: "CONTRIBUIÇÃO PARA O ESTUDO DA RESISTÊNCIA DE HELMINTOS GASTROINTESTINAIS DE OVINOS (Ovis aries) A ANTI-HELMÍNTICOS, NO ESTADO DO PARANÁ".}

Utilizando-se o teste de redução de ovos por grama de fezes, foi realizado um levantamento da situação da resistência dos helmintos gastrointestinais de ovinos (Ovis ories) frente a anti-helmínticos. Os testes foram realizados em 5 regiões climáticas do Estado do Paraná, trabalhando-se com infecções naturais a nível de campo. Nos testes foram utilizados 10 princípios ativos e 3 associações, abrangendo os 3 principais grupos químicos dos anti-helmínticos de amplo espectro (benzimidazóis, imidazotiazóis e avermectinas) e o closantel, como droga de espectro reduzido. Adotando-se o critério de eficácia superior a 90\%, a resistência está presente em $92,3 \%$ dos rebanhos testados para o oxfendazol, em $80 \%$ para o levamisol, em $85,7 \%$ para o tetramisol, em $91,3 \%$ para o ivermectin, em 30,8\% para o moxidectin, em $85,8 \%$ para o closantel, e em $87,5 \%$ para as associações tetramisol + disofenol e oxfendazol + closantel. Os outros tratamentos propostos (albendazol, fenbendazol, abamectin, doramectin e oxfendazol + ivermectin) apresentaram $100 \%$ de resistência nos rebanhos testados. A resistência múltipla está presente em todos os rebanhos analisados, chamando a atenção para a possibilidade de falência do controle químico das parasitoses gastrointestinais em ovinos no Estado do Paraná. Para minorar esta situação, algumas medidas são sugeridas no presente trabalho, sendo que a mudança de atitudes por parte de ovinocultores, médicos veterinários e autoridades sanitárias do Estado é fundamental para o futuro da ovinocultura paranaense. 